\title{
O Indiciamento da Pessoa Jurídica nos Crimes Ambientais
}

ISABELLE VASCONCELLOS KISHIDA

Polícia Federal - Brasil

$$
\text { 然 }
$$

\section{RESUMO}

Este artigo pretende propor parâmetros para o indiciamento de pessoa jurídica em inquéritos sobre crimes ambientais. A partir da análise dos elementos do crime, em especial a culpabilidade da pessoa jurídica. Pretende-se discutir como é possível identificar tais elementos em investigações de crimes ambientais envolvendo empresas. O artigo também analisará a aplicabilidade da lei nº 12.850/13 a esses delitos. Por fim, após a releitura dos conceitos de autoria, fato ilícito e dolo para a pessoa jurídica, parte-se para uma análise da aplicação dos referidos conceitos ao caso concreto. Utilizou-se a investigação do desastre ambiental ocorrido em Mariana, envolvendo as empresas Vale, Vog BR e Samarco.

Palavras-Chave: Responsabilidade Penal. Pessoa jurídica. Culpabilidade. Direito Ambiental. Crimes Ambientais. indiciamento

\section{INTRODUÇÃ̃o}

O tema da presente pesquisa é o estudo da imputação de responsabilidade penal da pessoa jurídica no âmbito dos crimes ambientais. A relevância da discussão do tema advém da existência de um certo grau de dificuldade para se aferir a responsabilidade do ente moral em inquéritos que cuidam do referido assunto.

Existem duas principais teorias a respeito da responsabilidade, a dupla imputação e a teoria da responsabilização direta. De acordo com a primeira, para restar configurada a responsabilização da pessoa jurídica nos crimes ambientais, exige-se a imputação de uma conduta delituosa a uma pessoa físi- 
ca, a qual estaria atuando em nome da empresa. No direito norte-americano a reconhecem como "vicarious liability". A segunda teoria sustenta a ausência de vinculação da responsabilização de uma pessoa física com a responsabilização da pessoa jurídica, pois a responsabilidade da empresa é independente da caracterização da responsabilização de uma pessoa física.

Considerando a brevidade do presente estudo, parte-se da premissa de que a teoria da responsabilização direta permite uma imputação da pessoa jurídica sem desrespeitar os parâmetros de culpabilidade e sem implicar em imputação de responsabilidade objetiva, o que violaria em última análise, a ordem constitucional.

Esta pesquisa pretende definir os parâmetros que devem ser observados na imputação de responsabilidade à pessoa jurídica. Para isso, vislumbra-se necessário o escrutínio da conduta do ente corporativo, para se compreender a formação da vontade e da ação que poderão dar azo a condutas criminosas por parte da empresa, o que deve ser observado em inquéritos envolvendo pessoas jurídicas.

Outra hipótese de questionamento é a caracterização da imputabilidade. Quais empresas estariam sujeitas a esse tipo de responsabilidade? Este artigo também pretende verificar a possibilidade de aplicação da Lei 12.850/13 a hipótese a de uma empresa que atue na forma de uma organização criminosa, com estrutura voltada para o cometimento de delitos, antes mesmo de se apresentar como uma estrutura corporativa.

A ausência de parâmetros claramente estabelecidos na lei $n^{\circ}$ $9.605 / 98$, lei de crimes ambientais, a existência de parca jurisprudência sobre o assunto e raríssima doutrina que possa auxiliar no estudo a fim de definir, a partir de quais parâmetros, deveria ser feito o indiciamento da pessoa jurídica nos crimes ambientais, justificam o interesse pelo tema.

A importância da pesquisa acerca do tema ganhou destaque após uma mudança na jurisprudência nos tribunais superiores sobre o cabimento da teoria da dupla imputação na responsabilização de entes morais. Inicialmente, o Superior Tribunal de Justiça ${ }^{1}$ entendia que a responsabilização da pessoa jurídica nos crimes ambientais deveria estar caracterizada na conduta de uma pessoa física, exigindo-se uma dupla imputação entre a atuação da

$1 \quad$ REsp 865.86 
empresa e da pessoa física. Em novos julgados sobre o tema, o Supremo Tribunal Federal ${ }^{2}$ (STF) entendeu que a referida exigência de dupla imputação não se justificava, posto que dificultava a caracterização da responsabilidade da pessoa jurídica nos crimes ambientais.

Desta forma, anteriormente, seguia-se o critério da dupla imputação, sendo que o indiciamento da pessoa jurídica deveria ter como base a conduta de uma pessoa física atuando em conformidade com os interesses da empresa. Após a mudança de jurisprudência, adotando-se a teoria da responsabilização direta, a qual independe da dupla imputação para se caracterizar a responsabilidade, entendo que é necessário um estudo para se definir em que bases deve ser feita a imputação, já que não mais se considerará o referencial da ação de uma pessoa física na imputação de responsabilidade à pessoa jurídica.

Antes mesmo da virada jurisprudencial acima descrita, o doutrinador espanhol Carlos Gomez- Jara Diez já defendia a tese da responsabilidade direta da pessoa jurídica nos crimes ambientais. No mesmo sentido, foi escrita a tese de doutoramento de Leandro Sarcedo, a qual baseia-se na idéia de fato próprio culpável social.

O legislador constituinte ao prever a responsabilização criminal da PJ não adotou de forma expressa qualquer modelo de responsabilização penal. Nem mesmo o legislador ordinário o fez, ao redigir a lei no 9.605/98.

Acredito que, a fixação de parâmetros para a imputação de responsabilidade penal à pessoa jurídica, sem implicar em responsabilidade objetiva, poderá auxiliar no estabelecimento de balizas a partir das quais será possível realizar o indiciamento da pessoa jurídica, de grande utilidade nas investigações acerca de crimes ambientais, diante da lacuna legislativa sobre o assunto na lei $n^{\circ} 9.605 / 98$.

O atuar da pessoa jurídica deverá ser considerado a luz da teoria das organizações para se delimitar a conduta que ensejou a responsabilização da pessoa jurídica nos crimes ambientais, assim como o dolo. O estudo pretende identificar e analisar a atuação de empresas em crime ambiental.

A partir da análise do IPL utilizado como base de dados, é que se pretende fixar uma metodologia para a imputação de responsabilidade à pessoa

2 RE 548181/PR - 1 ${ }^{\text {a }}$ Turma do STF 
jurídica, sugerindo-se tópicos que devem ser observados por parte da Autoridade Policial no momento do indiciamento.

A pesquisa pretende apontar critérios e parâmetros para o indiciamento de pessoa jurídica em crimes ambientais, em inquéritos dessa natureza, na imputação de responsabilidade penal da pessoa jurídica. Na seção 1, discorre-se acerca da responsabilidade penal da pessoa jurídica nos crimes ambientais. Na seção 2, expõe-se os requisitos para a configuração da referida responsabilização do ente moral. Nas seções seguintes discute-se o indiciamento da pessoa jurídica e a formação de sua culpabilidade. Na seção estudo de caso, a partir da análise da conduta de pessoas jurídicas em inquérito que apurou crimes ambientais no desastre ocorrido em Mariana, a pesquisa pretende verificar como deve ser construída a culpabilidade do ente moral, dissociada da culpabilidade individual.

Este estudo utiliza o IPL no $1843 / 2015$ que apurou os crimes ambientais dos arts. $54, \S 2^{\circ}$, I, III, IV e V, cominado com o art. 63, da Lei dos crimes ambientais, como fonte de dados para a elaboração deste artigo. A referida investigação teve como objeto o desastre ambiental ocorrido em Mariana, provocado pelo derramamento de lama e culminou no indiciamento de três pessoas jurídicas.

Pretende-se analisar quais as bases para a realização dos indiciamentos sob uma abordagem crítica, à luz do construtivismo, proposto por Carlos Gómez-Jara Díez, entre as teorias acerca da responsabilização da pessoa jurídica.

\section{A responsabilidade penal da pessoa jurídica nos CRIMES AMBIENTAIS}

Atualmente, muitas corporações empresariais têm atuação internacional, sendo que, em muitos casos, é responsável por receitas que são maiores que o PIB de alguns países. Desta forma, vislumbra-se a importância da atuação desses atores sociais como "global players", havendo uma necessidade premente de se conferir cidadania a tais entes.

Verifica-se que a pessoa jurídica, assim como a pessoa física, é sujeito de direitos e obrigações sociais. No caso de atuação empresarial que importe em danos a terceiros, indiscutivelmente a empresa será processada, por ser 
considerada civilmente responsável, a exemplo de pessoas físicas, quando causem danos a terceiros.

A adoção da responsabilidade penal da pessoa jurídica por parte de muitos países como Inglaterra, Estados Unidos, Colômbia, na seara do direito penal se justifica por várias razões. Inicialmente, constata-se a dificuldade do legislador prever toda e qualquer possibilidade de perigo no universo empresarial que importe um risco à sociedade. Podemos citar diversos exemplos de episódios em que a atividade empresarial importou em um incremento de custo social enorme, sem que o direito se posicionasse para a imposição de sanções. Um forte exemplo é a tragédia ocorrida em Chernobyl, assim como o desastre ocorrido em Mariana, Minas Gerais.

A cominação de sanção penal busca incentivar que os membros da sociedade adotem um comportamento social adequado, o que para uma pessoa jurídica, equivale dizer, que esta deverá não apenas cumprir as leis, mas para o direito ambiental é relevante que ela não atue de forma a criar risco não permitido, o qual não deve ser suportado pelo Estado, mas por aquele que se aproveitou do lucro gerado por tal incremento, como dispõe o princípio do poluidor pagador e do usuário pagador.

Em verdade, não é possível que o Estado, e nem mesmo o legislador, prevejam todos os riscos que a atividade empresarial poderá criar. Todavia, relegar à sociedade o custo de tais riscos é deixar que a pessoa jurídica apenas goze do lucro sem as possíveis consequência de sua atuação. É possível que parte desses riscos sejam mitigados ou minimizados por condutas mais cautelosas por parte das empresas e pela adoção de sistemas de compliance em complementação à observância e respeito da respectiva legislação administrativa em matéria ambiental.

A lei de crimes ambientais, lei $n^{\circ} 9605 / 98$, ao prever diversos tipos de crimes ambientais tem como principal objetivo a reparação do dano ambiental. Não visa o encarceramento, mas busca a reparação do dano e atuação na prevenção geral primária, para evitar a ocorrência do fato típico, já que a PJ poderá ter sua dissolução judicial decretada, o que equivaleria à uma pena de prisão, se comparado à pessoa física.

A maior parte das condutas tipificadas permite a utilização de institutos despenalizadores previstos na lei 9.099, como a transação penal, suspensão condicional da pena e sursis, os quais terminam por obrigar o autor 
de ilícito ambiental a reparar o dano com maior veemência, caso se compare com a imposição de infrações administrativas.

\section{I.I. REQUISITOS PARA CONFIGURAÇÃO DE RESPONSABILIDADE PENAL DA PJ}

Quando se discute a responsabilização penal da pessoa jurídica, há que se ter em mente que nem toda a ação de uma pessoa física pode gerar responsabilidade penal da pessoa jurídica. Para que a conduta de uma pessoa física implique na imputação de responsabilidade, de acordo com o art. $3^{\circ}$ da lei no $9.605 / 98$, exige-se que: "a infração tenha sido cometida por decisão do representante legal ou contratual, ou de seu órgão colegiado, mas sempre no interesse". Se o ato imputado foi uma decisão isolada de um funcionário, e não foi em benefício ou interesse da empresa, ou seja, visando o lucro ou diminuição de custo, não estarão presentes os requisitos. Vladimir Passos de Freitas defende que no caso de decisão de colegiado, a vantagem é presumida.

Para Carlos Gomez- Jara Diez, nas sociedades complexas ocorre uma pulverização das atividades da empresa, o que implica em uma descentralização na tomada de decisões por parte da empresa. Há que se ressaltar que a formação da vontade, no caso da pessoa jurídica, surge de forma diversa da maneira como ocorre nos seres humanos.

A responsabilização surge da capacidade da expressão de vontade e autonomia para agir de forma diversa, retirando a consciência humana do centro da imputação de responsabilidade, para colocar a autorreferenciabilidade ${ }^{3}$ da pessoa jurídica.

Este estudo adota como mais acertada a teoria da imputação direta da responsabilidade da pessoa jurídica, tendo em vista que é o modelo que mais atende aos ditames constitucionais, pois não limita a sua configuração. Dessa forma, como ressalta (Bello Filho $)^{4}$, mesmo que não configurada a responsabilidade da pessoa físíca, por falta de conhecimento dos elementos intrínsecos à responsabilização, não será o caso de afastamento da responsabilidade do ente moral. Trata-se de responsabilidades complementares, com premissas diferentes para a sua configuração.

3 Gomez-Jara, Carlos. A responsabilidade penal da pessoa jurídica - Teoria do Crime para Pessoas Jurídicas, Atlas, São Paulo, 2015.

4 Bello Filho, Ney de Barros. Responsabilidade Criminal da Pessoa Jurídica por crimes contra o meio ambiente: um balanço após 27 anos de Constituição, Revista de Direito Ambiental, ano 20, vol.80, Out-Dez, 2015 
A Min. Rosa Weber manifestou-se no mesmo sentido, em seu voto no Recurso Extraordinário n ${ }^{\circ} 548181$, sustentando que a adoção da teoria da dupla imputação ${ }^{5}$ implica no estabelecimento de cláusula limitadora da aplicação direta do art. $225, \$ 3^{\circ}$, da Carta Magna, tendo em vista que a CF não impõe tal exigência para a caracterização.

Antes da análise da culpabilidade, é mister individualizar a conduta que supostamente dará azo à imputação de responsabilidade à PJ, estabelecendo-se o fato interna corporis da PJ apto a delinear tal responsabilidade. É possível que se verifique por meio de ação, como por exemplo, um defeito na organização da PJ ou por omissão, na ausência de controle externo da atuação da mesma.

Na seção seguinte será feita uma abordagem dos elementos do delito, para que, por fim, se enfrente a questão da culpabilidade nos delitos cometidos por pessoa jurídica.

\section{I.2 FATO TÍPICO}

Adotando-se a teoria finalista, temos como elementos do fato típico a conduta, o resultado (dano), o nexo causal e a tipicidade. No estudo da delinquência empresarial no direito ambiental, a conduta compreende o agir com voluntariedade destinado a um fim. Em relação à Pessoa Jurídica, essa atuação delituosa terá como finalidade não apenas a obtenção do lucro, mas compreende ainda a ação deliberada à diminuição de custo da empresa.

No tocante à voluntariedade da conduta, é possível afirmar que uma pessoa jurídica que adotou todos os esforços práticos para evitar que uma conduta implicasse em consumação de crime, ainda que ocorra algum resultado típico (dano), esta não pode sofrer imputação penal. Conclui-se que, quando uma pessoa jurídica adotou mecanismos efetivos que razoavelmente poderiam detectar e deter a consumação de um crime por parte de seus funcionários, ainda que este resultado ocorra, atingiu-se a prevenção geral que fundamenta a imposição de penas às pessoas jurídicas (Weissmann).

Quando se analisa a consumação de fato típico imputado à PJ, deve restar claro que o dano causado por essa conduta realizada em nome e em

5 condiciona a imputação de responsabilidade penal à pessoa jurídica a existência de imputação de responsabilidade a uma pessoa física ligada à pessoa jurídica. 
benefício da empresa apresenta nexo causal com esta ação. Como o foco do presente trabalho é a culpabilidade, item mais complexo na responsabilização da PJ, passamos ao próximo elemento do delito.

O dolo, quando se fala em responsabilização da pessoa física, pode ser conceituado pela teoria da vontade, segundo a qual, trata-se da vontade consciente de praticar a conduta dirigida a uma finalidade. No direito penal empresarial, segundo Gomez Jára, consiste no conhecimento organizativo, que se compõem do concreto risco empresarial nos delitos de perigo, que se realiza no resultado típico.

Sob o enfoque da teoria da representação, o dolo resta configurado quando o agente prevê o resultado danoso, mas ainda assim, prossegue com a conduta.

O dolo, localizado dentro da conduta da PJ, é a "vontade social", a qual se vincula à vontade dos órgãos dirigentes da empresa, que definem estratégias de atuação no mercado e de atuação administrativa da PJ. Também pode ser enxergado em situações nas quais, diante da criação de um risco não permitido, mesmo com a ciência dele, a PJ opta por uma conduta que deixa o meio ambiente, bem jurídico resguardado pela norma, desprotegido.

A culpa, para a pessoa física, compreende conduta humana voluntária, violação de um dever de diligência e um resultado naturalístico involuntário. No caso da pessoa jurídica, poderá ser constatada diante de defeito da organização da empresa, enquanto que o dolo importa na adoção de uma política criminógena por parte da empresa. Esses elementos poderão ser analisados a partir da identificação do fato referência (conduta criminosa) e do ato interna corporis e a previsibilidade do resultado.

\section{I.3. ILICITUDE OU ANTIJURIDICIDADE}

Ao se analisar o segundo substrato do crime, a ilicitude, adotandose o conceito analítico de crime, esta deve ser encarada como conduta típica não justificada, ou seja, que se contrapõe ao ordenamento jurídico (Sanches).

Nos crimes ambientais cometidos por pessoa jurídica, a ilicitude do fato restará demonstrada na não observância da posição de garantia da pessoa jurídica no caso de conduta possivelmente danosa ao meio ambiente, ou em 
situações nas quais a atuação da empresa ignore, por exemplo, as determinações impostas no curso de um licenciamento ambiental, ou disposições de regulação administrativa que objetive resguardar a tutela do meio ambiente, as quais resultem em um incremento do risco de dano ambiental a ponto de tornar a conduta ilícita.

\section{I.4. CULPABILIDADE DA PESSOA JURÍDICA}

A responsabilização da Pessoa Jurídica (PJ) no direito penal requer que sejam delimitados critérios mínimos para que esta responsabilização seja feita de forma racional, limitada e observando-se os princípios constitucionais garantidores de um processo penal democrático.

Em regra, o conceito clássico de culpabilidade sempre esteve ligado à conduta humana. Contudo, a culpabilidade não se limita à idéia de um juízo de reprovabilidade pessoal que recai sobre o autor de um fato típico e ilícito, que pode se comportar de acordo com o direito, mas opta livremente, por agir contrariamente ao direito. Essa vontade do ser humano em optar por agir em contrariedade ao direito é possível de ser demonstrada no âmbito da PJ.

É possível construir um conceito de vontade que englobe a pessoa jurídica, ainda que esta se forme de maneira distinta da vontade humana. A formação da vontade coletiva que vai representar a voluntariedade da conduta da PJ é que deve ser objeto de sistematização ao se analisar a culpabilidade da PJ.

A teoria da Realidade, ou da Personalidade orgânica, elaborada por Otto Gierke estatui que a pessoa moral não é um ser artificial, criado pelo Estado, mas sim um ente real (vivo e ativo), dotada de vontade própria, com capacidade de agir e praticar ilícitos penais ${ }^{6}$. Destaca a independência da pessoa jurídica dos indivíduos que a compõe, ressaltando que a responsabilidade civil e penal são autônomas.

A culpabilidade deve ser estabelecida tendo por base o comportamento da empresa, e não fato de terceiro, que pode ser responsabilizado indi-

6 Freitas, Gizele Luzia de Mello de; Spenger, Adriana Maria Gomes de Souza. A possibilidade de responsabilização penal exclusiva da pessoa jurídica em crimes ambientais. Revista Eletrônica de iniciação Científica. Itajaí, Centro de Ciências Sociais e Jurídicas da UNIVALI, v. 4, n.1, p. 921-942, $1^{\circ}$ trimestre de 2013 . 
vidualmente. Em verdade, a responsabilização penal da PJ é complementar a da pessoa física, mas a empresa deve ser encarada como ator social.

Por óbvio, a interpretação do conteúdo da culpabilidade da PJ não pode se apegar aos mesmos princípios e garantias relacionados aos indivíduos como defendeu Juliana Barbosa. Não se pode aceitar a utilização de uma responsabilidade administrativa objetiva, a qual não prevê excludentes de ilicitude e que se utiliza de imputações genéricas para configurar a responsabilidade penal da pessoa jurídica.

Pretende-se analisar a culpabilidade no presente estudo à luz da concepção construtivista proposta por Gomez- Jara, tendo por base a dimensão organizativa da pessoa jurídica, os conceitos de fidelidade ao direito, como condição para a vigência da norma, e a capacidade de questionar-se a vigência da norma.

\subsubsection{ReQUISITOS}

A configuração da culpabilidade requer a presença da imputabilidade, potencial consciência da ilicitude e exigibilidade de conduta diversa, seguindo-se os ditames da teoria clássica do delito.

A pessoa jurídica pode se considerar imputável, quando se verificar a presença de liberdade de auto-organização, o que implica dizer que tem liberdade de ação, autonomia. Verifica-se que sua atuação não se encontra vinculada exclusivamente a uma pessoa determinada que é responsável pela tomada de decisão no centro administrativo, ou seja, aquela que decide todas as açóes da empresa. A maioridade penal da pessoa jurídica se constata e se justifica quando esta apresenta processos decisórios complexos, não estando a sua atuação vinculada à vontade de um ou mais sócios, mas a um conselho de administração, diretores, ou aprovação de atos por uma assembléia, por exemplo. Considerando-se a teoria do delito, equivaleria dizer que teria maioridade penal, da mesma forma que se constata a maioridade penal, ou capacidade de ação da pessoa física, ao considerá-la imputável ou não.

O mesmo não ocorre quando se verifica que a pessoa jurídica apresenta estrutura familiar, com poucos funcionários, quando a atuação da empresa é praticamente uma reflexão do comportamento de seu sócio gerente, carecendo de qualquer autonomia, pois a decisão tomada em nome da empresa é claramente individualizável em uma conduta da pessoa física, que atuou de forma individual. 
Em verdade, a atuação de uma empresa é resultado de uma sequência de ações de diversas pessoas, que juntas, no curso dos processos de tomada de decisão do ente moral, compõem o atuar da empresa. $\mathrm{O}$ agir é único, todavia sequenciado de um conjunto de atuações, decisões que dificilmente podem ser materializadas em um único ato de uma única pessoa.

A desnecessidade de dupla imputação nos crimes ambientais, à medida que facilita a delimitação de responsabilidade do ente corporativo, lança novos desafios ao Delegado de Polícia no momento do indiciamento.

A individualização da responsabilidade das empresas deve ser pautada a partir da identificação de como funcionam os processos: decisório e de atuação da empresa, pois a partir daí é possível analisar-se a conduta do ente moral.

A potencial consciência da ilicitude no caso de pessoa jurídica, ou seja, a sua censura, não se confunde com a reprovação individual essencial. Esse elemento da culpabilidade se consubstancia na ciência do risco que determinada ação ou omissão acarreta ao meio ambiente. $\mathrm{O}$ reconhecimento de uma esfera de autonomia à empresa para fins de sua própria organização exige, em contrapartida, que esta seja fiel ao direito, ou seja, esta autonomia implica na responsabilidade de uma conduta proba e de que seus resultados sejam alcançados observando-se as regras legais.

A exigibilidade de conduta diversa, para a pessoa física, importa na possibilidade de se exigir comportamento diverso daquele adotado na ocorrência do fato típico. A pessoa jurídica não se esquiva de tal dever, que é facilmente compreendido na impossibilidade desta em aumentar ou criar risco não permitido pelo direito. Geralmente se verifica a sua ocorrência em condutas que buscam mais lucro para a empresa, ou que visam a diminuição de despesas, em detrimento da segurança e proteção do meio ambiente.

Contudo, a responsabilização penal do ente moral nos crimes ambientais requer, ainda, de acordo com o art. $3^{\circ}$ da lei $9.605 / 98$, que a infração seja cometida por decisão do representante legal ou contratual, ou do órgão colegiado, da pessoa jurídica, no interesse ou benefício da sua entidade.

O requisito de Representação legal pode ser compreendido como a necessidade de que a conduta ora imputada à $\mathrm{PJ}$ tenha ocorrido por pessoa física ligada de alguma forma à PJ beneficiada, mas que tenha algum poder de decisão para ter atuado em nome da empresa. Caso se admita que ato de 
qualquer funcionário implique em responsabilidade da PJ, é possível que empregados subalternos sem qualquer poder de decisão sejam capazes de gerar responsabilidade à PJ. Por derradeiro, isso dificultará a observação da presença do segundo requisito, que se passa a expor.

A atuação no interesse e proveito da empresa, segundo requisito a ser observado, significa dizer que a ação ou omissão deverá importar em lucro ou vantagem direta ou indireta para a PJ. Não se justifica o indiciamento da PJ, no caso em que o ato praticado tenha importado apenas em vantagem para a pessoa física, que o executou em nome da empresa. Todavia, se implicar em vantagem indireta à PJ, justifica-se a imputação de delito a ela.

Além dos requisitos expostos no art. $3^{\circ}$ da lei de crimes ambientais, é possível que sejam observados outros elementos para a imputação de responsabilidade. Uma questão relevante é saber se a empresa possui procedimentos e políticas razoáveis e efetivas para a prevenção de ações danosas ao meio ambiente, ou ainda, se a conduta da empresa cria ou implementa um risco não permitido.

Outro tópico que pode ser levado em consideração é verificar se houve omissão por parte de diretores ou presidente da empresa por atos de seus empregados subordinados que impliquem em danos ou criação/implementação exacerbada de risco não permitido.

\section{INDICIAMENTO DA PESSOA JURÍDICA}

O indiciamento, em que pese ser utilizado nas esferas penais, administrativas e políticas (Branco), aqui terá tratamento apenas na esfera penal. Trata-se de ato privativo do Delegado de Polícia, e ocorre quando as provas e indícios apurados no curso do inquérito apontam a autoria do delito investigado para um suspeito, conforme o exposto na lei $\mathrm{n}^{\circ} 12.830 / 13$, em seu art. $2^{\circ}, \S 6^{\circ}$. No dizer de Branco, não se trata de um juízo de absoluta certeza.

Diante da ausência de robusta regulamentação legal acerca do indiciamento $^{8}$, é importante que se passe a observar como a jurisprudência vem

$7 \S 60 \quad \mathrm{O}$ indiciamento, privativo do delegado de polícia, dar-se-á por ato fundamentado, mediante análise técnico-jurídica do fato, que deverá indicar a autoria, materialidade e suas circunstâncias.

8 Apenas uma breve menção no art. $6^{\circ}$, V, do CPP, remetendo aos artigos referentes ao interrogatório judicial as mesmas garantias ao acusado em sede policial. 
tratando este tema. O STF se manifestou de forma contrária ante a possibilidade de indiciamento por determinação por parte de magistrado, afirmando que o ato de indiciamento é de atribuição exclusiva de autoridade policial, não sendo possível o indiciamento após o recebimento da denúncia?

A despeito do fato de que o indiciamento baseia-se no livre convencimento do Delegado de Polícia, deve anteceder ao indiciamento, despacho fundamentado no qual sejam expostas as razões que embasam o ato. A respeito do tema, é importante destacar decisão do Supremo Tribunal Federal (STF), in verbis:

EMENTA: Inquérito Policial. Despacho genérico de indiciamento referente a diretor de entidade, por fato que teria ocorrido durante gestões anteriores. Indiciamento precipitado, não justificado, que constitui evidente constrangimento ilegal. Recurso de habeas corpus parcialmente concedido. (HC 8466/PR; Habeas Corpus $n^{\circ}$ 1999/0003165-2, Rel. Min. Felix Fisher). ${ }^{10}$

No caso da pessoa jurídica, o presidente da investigação não se desincumbe do ônus de fundamentar o indiciamento, pois este, ainda que não realizado em face de pessoa física, mas em desfavor da pessoa jurídica, poderá importar em dano à honra da PJ, pois fere a imagem corporativa positiva, ou seja, de empresa que segue os padróes éticos estabelecidos e a lei.

O status de indiciado, conforme o Min. Sepúlveda Pertence ${ }^{11}$, permite a este invocar plena e ostensivamente as garantias consequentes, entre as quais a de silenciar-se a respeito da imputação a ele irrogada.

Não restou estabelecido na legislação o momento em que deve se dar o indiciamento. Em regra, no curso da prática penal, ele ocorre no momento em que o suspeito é ouvido, ou seja, no momento do interrogatório do investigado que passa a ser ouvido em sede policial na forma de acusado, e não como testemunha.

Por certo, na ausência de comparecimento, é possível a realização de indiciamento indireto. No caso da pessoa jurídica, deve ser ouvido não o

9 in: HC 115.015-SP julgado em 27/08/2013- 2a Turma do STF

10 Apud: Moreira, Romulo Andrade. O indiciamento e o STF. Repertório de Jurisprudência RJ $3.01 / 12$ n 9, maio, 2016.p.301

11 na análise da questão exposta na petição no 3825 , no plenário do STF, do Inq $n^{\circ} 2411$, Operação

Sanguessuga 
presidente da empresa ou diretor, ou seja, pessoas que possivelmente não tem conhecimento dos fatos ora sob investigação. É relevante que no momento da oitiva do representante legal da PJ, a Autoridade Policial esteja diante de pessoa que possa, de alguma forma, ter conhecimento dos fatos sob investigação e assim possa, efetivamente, representar a PJ. Nesse sentido, José Paulo Baltazar Júnior, citando o MS 2002.04.01.013843-0, TRF4, Germano, 7 a Turma, 26.02.2003.

Desta forma, vislumbra-se a relevância e impacto do ato de indiciamento no curso da persecução penal, e as responsabilidades que o mesmo requer para sua correta execução por parte da Autoridade Policial, diante de suas consequências jurídicas e morais. A importância da presente discussão fundamenta-se no fato de que o ato de indiciamento, privativo da Autoridade Policial, é um ponto nodal para futuro oferecimento de denúncia por parte do Ministério Público e, podendo ainda, ser utilizado em ação civil pública ou em ações de reparação civil dos danos causados.

Tendo em vista que na maioria dos crimes ambientais as provas serão produzidas no curso do inquérito policial, ante a ação do tempo e a rápida alteração do meio ambiente, a caracterização de responsabilidade penal do ente moral por parte da Autoridade Policial é de crucial importância, podendo repercutir em várias searas do direito. Se a produção de provas no curso do inquérito for robusta, e na maioria dos casos deve ser, em função da ação do tempo em matéria ambiental, estas poderão dar azo a processo de reparação civil e até mesmo servir de base para a imposição de multas administrativas. $\mathrm{Na}$ maioria dos casos, a prova de um desmatamento, de poluição não será produzida em juízo, mas no curso de um inquérito, sendo apenas submetida ao contraditório na fase judicial.

\section{A INCIDÊNCIA DA LEI No 12.850/13 EM CRIMES AMBIENTAIS COMETIDOS POR PESSOA JURÍDICA}

A lei das organizações criminosas, lei no $12.850 / 13$, pode ser aplicada aos membros de uma PJ que se associem por meio de uma empresa para a prática de crimes ambientais, em que a pena cominada seja superior a quatro anos, como nos delitos do art. 35 (pesca com a utilização de explosivos ou substâncias tóxicas), art. 40 (dano a Unidade de Conservação), $\$ \$ 2^{\circ}$ e $3^{\circ}$, do art. 54 (crime de poluição qualificada ou no caso de omissão de medidas de 
precaução em caso de risco de dano ambiental grave ou irreversível), art. 69A (elaboração ou apresentação de laudo, estudo ou relatório ambiental total ou parcialmente falso no curso de licenciamento ambiental ou concessão florestal), todos da lei de crimes ambientais, ainda que instituída de forma legal.

Deve se atentar para o fato de que a referida lei foi publicada em 2013, sendo que somente fatos ocorridos após esta data poderão implicar na imputação do referido delito.

Para ilustrar a proposição acima, tome-se por base o seguinte exemplo. Um grupo de pessoas constituiu a empresa $\mathrm{X}$ para a exploração da pesca mediante a utilização de explosivos, o que constitui o delito do art. 35 da Lei $\mathrm{n}^{\circ} 9.605 / 98$. Caso esse grupo seja composto por quatro ou mais pessoas, que, de maneira organizada e estável, utilizam a pessoa jurídica e por meio desta se associam para cometer ilícitos com pena cominada superior a 4 quatro anos, os membros da referida pessoa jurídica podem ter a imputação do delito de organização criminosa, ainda que no curso de investigação para a apuração de crimes ambientais.

É uma hipótese curiosa, tendo em vista que grande parte dos deli-

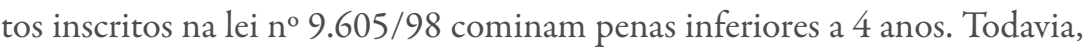
é possível a incidência do art. $2^{\circ}$ da lei $n^{\circ} 12.850 / 13$ nas investigações envolvendo crimes ambientais, caso os representantes ou sócios de uma pessoa jurídica se associem de forma não esporádica, em contraposição ao mero concurso de pessoas, para obtenção de vantagem de qualquer natureza, mediante a prática de crimes, conforme o $₫ 1^{\circ}$, do art. $1^{\circ}$ da referida lei.

Ao se verificar que os membros da pessoa jurídica constituem uma ORCRIM, restando tipificado o crime do art. $2^{\circ}$, da lei $12.850 / 13$, a persecução criminal é direcionada às pessoas físicas que a compõem, tendo em vista a ausência de previsão legal para apenar-se a pessoa jurídica em tais casos.

De outro giro, nessas hipóteses, em que se verifique que a pessoa jurídica possui finalidade defraudatória deliberada, deverá ser desconsiderada a personalidade jurídica, pois esta não pode ser utilizada como um véu para encobrir os verdadeiros autores, tendo por base o art. $4^{\circ}$ da Lei de Crimes Ambientais e artigo 91, II, b, do Código Penal.

Prima facie, parece contraditória a responsabilização da pessoa jurídica no âmbito criminal e sua desconsideração no plano cível, para possi- 
bilitar a reparação de danos, mas em verdade, essas medidas visam a tutela eficiente do meio ambiente, coadunando-se com o art. 225 da CF, como (Feliciano) defende.

Caso os membros da referida organização criminosa (ORCRIM) tentem embaraçar, frustrar ou impedir a investigação de crimes cometidos por ela, também estarão incorrendo em crime, conforme o exposto no art. $2^{\circ}$, $\S 1^{\circ}$ da Lei $n^{\circ} 12.850 / 13$.

Desta forma, conclui-se que é possível a utilização da lei no ${ }^{\circ} 12.850 / 13$ nas hipóteses de investigaçôes de crimes ambientais com penas cominadas superiores a 4 anos, quando estes são cometidos por pessoa jurídica, caso a utilizem de forma deliberada, de maneira estável, não eventualmente para cometer tais delitos. Há que se atentar que a imputação nos casos dos arts. $2^{\circ}$ caput e seu $₫ 1^{\circ}$ deve ser direcionada em face das pessoas físicas que a compõem e que tem poder de direção sob a ação desta, tendo em vista a ausência de previsão legal para responsabilização direta da PJ.

\section{Estudo de Caso}

$\mathrm{O}$ rompimento da barragem de Fundão, que ocasionou um dos maiores desastres ambientais da atualidade, em Mariana, atingindo diversas cidades vizinhas, vai ser utilizado como estudo de caso. Esse fato foi objeto do IPL n ${ }^{\circ} 1843 / 2015$, o qual deu origem a denúncia oferecida por parte da Força Tarefa Rio Doce, formada pela Procuradoria da República no Estado do Espírito Santo e no Estado de Minas Gerais. O referido inquérito apurou os crimes ambientais dos arts. $54, \S 2^{\circ}$, I, III, IV e V, cominado com o art. 63, da Lei dos crimes ambientais

Em função da brevidade do estudo, apenas a atuação da Samarco será analisada. A responsabilidade da pessoa jurídica envolvida nos fatos sob investigação pode ser sistematizada da seguinte forma, ao se adotar os parâmetros propostos pelo presente estudo.

O fato referência do caso ora sob observação é o desastre ambiental provocado pelo rompimento da barragem de Fundão, resultando na poluição do Rio Doce e na destruição de cidade histórica, condutas tipificadas nos arts. $54, \$ 2^{\circ}$, I, III, IV e V, cominado com o art. 63, da lei de crimes ambientais. 
Inicialmente, partindo-se para a individualização da conduta das pessoas jurídicas envolvidas, foi apurado ao longo das investigações que os erros técnicos de implementação da barragem de Fundão e sua manutenção foram manipulados para reduzir os custos das empresas envolvidas na utilização da estrutura danificada, para o aumento de dividendos, e ainda para reduzir o tempo de paralisação da operação da referida barragem, em caso de realização das obras necessárias, observandose as especificações técnicas do projeto inicial.

O dique 1 da barragem de Fundão apresentava problema de drenagem ante a má construção da barragem. A Vale, a Samarco e a BHP tinham ciência de que o correto, ou seja, a conduta esperada por uma empresa que atue conforme a lei e o direito no caso concreto, seria descomissionar a barragem e construir outra dentro das especificações projetadas.

Contudo, as referidas empresas decidiram adotar a "solução" mais barata, ou seja, realizar mais remendos, o que permitiria um rápido reinício das operações, de acordo com a exposição dos fatos na denúncia oferecida pela força tarefa que cuida da ação penal proposta, tendo por base o IPL $n^{\circ}$ 1843/2015, concluído por parte da Polícia Federal em Minas Gerais.

Há que se observar ainda, que no plano de contingenciamento da Samarco não constava a periodicidade de monitoramento e apresentava falhas na comunicação. De acordo com o que foi apurado no curso da investigação, o plano de ações emergenciais da barragem de Fundão era pro forma e sem eficácia. Um exemplo para ilustrar a ineficácia do plano é o fato de que a comunicação, em caso de desastre, deveria ser feita por telefones, em áreas onde o sinal telefônico é difícil, não sendo confiável. Não havia a previsão de alarmes sonoros. Isto demonstra o enorme descaso com que era tratado por parte da Samarco a possibilidade de desastre (risco) e ainda, que a organização da empresa era falha, pois era possível empreender um plano de ações emergenciais que fosse mais eficiente.

Outro fato que corrobora a inexistência de uma organização diligente da empresa para a prevenção de desastres ambientais é constatação de que os instrumentos de medição da barragem apresentavam defeito, o que impossibilitava uma leitura periódica dos aparelhos. E a relevância do monitoramento não se deve apenas em relação à existência de erros na construção da barragem, mas também em função da constatação por parte da Samarco de problemas na ombreira esquerda da barragem. 
A co-autoria da empresa Vale na empreitada criminosa se deve em atenção à existência de contrato celebrado entre a SAMITRI (atual Vale) e a Samarco S/A para lançamento de lama na mina Alegria, na barragem da Samarco, constando, inclusive, que a SAMITRI (Vale) participará das despesas de manutenção da atual barragem e de construção de novas barragens, bem como eventuais custos ambientais decorrentes da utilização das barragens da Samarco que proporcionem o grau de utilização.

Vislumbra-se que a ausência de monitoramento, manutenção e utilização da barragem eram de responsabilidade da Vale, e desta forma, era usada em benefício da empresa, como requer o art. $3^{\circ}$ da lei 9.605/98.

No tocante ao dolo na conduta das pessoas jurídicas envolvidas, este é facilmente constatado a partir da ciência do risco empreendido com a não correção dos erros no projeto e construção da referida barragem. No caso ora sob estudo, de acordo com a denúncia do Ministério Público Federal, havia relatório interno da Samarco no qual foi aventado claramente a probabilidade do rompimento da barragem de Fundão. A denúncia ressaltou que o referido relatório era tão preciso que havia a previsão de morte de cerca de 20 pessoas no caso de rompimento da barragem de Fundão, sendo que, ocorreram 19 mortes de fato.

Há que se acrescentar, que a lei $n^{\circ} 12.334 / 2010$, que estabeleceu a Política Nacional de Informações sobre a Segurança de Barragens em seu art. $4^{\circ}$, III, estabelece que o empreendedor é o responsável legal pela segurança da barragem, cabendo-lhe o desenvolvimento de ações para garantí-la ${ }^{12}$. Infelizmente, como acentuou Paulo Affonso Leme Machado, a referida lei impõe um dever de autofiscalização do empreendedor, que é o responsável pela realização de inspeções de segurança e elaboração de revisões periódicas de segurança.

Entendo que, no caso de um desastre, como o ocorrido, ora sob análise, o dever de diligência da empresa não foi cumprido e, consequentemente a previsibilidade da ocorrência de um dano era não só clara, como foi aumentada por parte das empresas envolvidas que se beneficiavam com tais ações para diminuir custos operacionais.

No tocante à aplicabilidade da lei $\mathrm{n}^{\circ} 12.850 / 13$ às pessoas físicas envolvidas nos fatos ora sob investigação, entendo que não se consumou o

12 Machado, Paulo Affonso Leme. Direito Ambiental Brasileiro, 22a ed. Malheiros: São Paulo. p.599 
delito do art. $2^{\circ}$ da referida lei, tendo em vista que, não restou configurada a hipótese do $₫ 2^{\circ}$ do art. $1^{\circ}$ da lei. Ainda que as empresas envolvidas, em destaque a Samarco, e alguns de seus funcionários e membros tenham sido responsáveis por omissão penalmente relevante quanto ao dever de garantia da segurança do empreendimento e atendimento às normas administrativas acerca da construção da barragem e ainda no tocante a sua manutenção, não é possível afirmar que as referidas empresas encontravam-se voltadas para a prática de crimes de forma estável e estruturada.

Vislumbro a ocorrência de concurso de pessoas físicas e jurídicas, como bem entendeu a Autoridade Policial responsável pelo inquérito, o que restou confirmado no oferecimento da denúncia por parte da Força Tarefa do Ministério Público Federal.

\section{Consideraçốes Finais}

Diante de todo o exposto ao longo do presente estudo, verifica-se a necessidade de criação e sistematização de uma teoria geral da pena direcionada à PJ, o que requer a elaboração de critérios mínimos para que a responsabilização do ente moral se realize de forma racional e limitada, respeitandose os princípios básicos do direito penal.

Imputar responsabilidade penal à PJ dissociada da responsabilização de uma pessoa física tem o objetivo de obrigar uma empresa a adotar medidas que barrem condutas criminosas de seus empregados ou diretores, adotadas possivelmente em nome e benefício da empresa. O modelo de dupla imputação de responsabilidade (vicarious liability) não incentiva as empresas à implementação de políticas de prevenção de danos e compliance, pois esse modelo de responsabilização permite que qualquer conduta equivocada do empregado da PJ possa implicar em responsabilização da PJ, por não contar com critérios direcionados à PJ.

$\mathrm{Na}$ ausência de uma clara identificação dos elementos fundantes da culpabilidade no indiciamento da Pessoa Jurídica, corre-se o risco de uma imputação de responsabilidade objetiva e ainda, de se ferir de morte o princípio do devido processo legal, garantido pela constituição, que torna obrigatória a observância da presunção de inocência, do princípio da legalidade, e do ônus da acusação de provar os fatos imputados ao acusado. O combate à criminalidade não pode ser feito à margem da legitimidade do sistema utilizado. 
No dizer de Giacomolli, a circunstância de ter sido reconhecida a culpabilidade da pessoa física que atua na corporação, nos crimes ambientais, não translada esta responsabilidade criminal, ipso facto, ao ente corporativo. Caso se pense de forma diversa, toda pessoa física que seja ligada a uma pessoa jurídica que tenha a ela imputado um crime ambiental, necessariamente implicará em responsabilização da respectiva empresa.

ISABELLE VASCONCELLOS KISHIDA

Delegada de Polícia Federal, lotada na Superintendência Regional do Rio de Janeiro

E-MAIL: ISABELLE.IVK@DPF.GOV.BR

INDICTMENT OF LEGAL ENTITY ON ENVIRONMENTAL Crimes

ABSTRACT

This paper intends to list parameters for indictment of a legal entity on investigations about environmental crimes. Looking into the components of a criminal offense, especially mens rea of the legal entity, it questions the possibility of identification of those elements in environmental crimes investigations involving corporations. At last, after a reshape on the elements of a criminal offense reffered to a legal entity, a case study will be the object of analysis. The disaster ocurred in Mariana involving Vale, $\operatorname{Vog}$ Br and Samarco was chosen for that.

Keywords: Criminal Corporate Liability. Legal entity. Culpability. Environmental Law. Environmental Crimes. Indictment

\section{La Acusación de la Persona Jurídica en los Crímenes Ambientales}

\section{RESUMEN}

Este artículo pretende proponer parámetros para la inculpación de persona jurídica en investigaciones sobre crímenes ambientales. A partir del análisis de los elementos del crimen, en especial la culpabilidad de la persona jurídica, se pretende discutir cómo es posible identificar tales elementos en investigaciones de crímenes ambientales que involucran empresas. El artículo también analizará la aplicabilidad de la ley n $12.850 / 13$ a esos delitos. Por último, tras la relectura de los conceptos de autoría, hecho ilícito y dolo para la persona jurídica, se parte para un análisis de la aplicación de dichos conceptos al caso concreto. Se utilizó la investigación del desastre ambiental ocurrido en Mariana/ MG, involucrando a las empresas Vale, Vog BR y Samarco 
Palabras Clave: responsabilidad penal. Persona jurídica. Culpabilidad. Derecho ambiental. delitos ambientales. acusación

\section{REFERÊNCIAS}

BALTAZAR JÚNIOR, José Paulo (2016). Legislação Penal Especial. Ed. Saraiva, $2^{a}$ ed. São Paulo.

BELLO FILHO, Ney de Barros (2015). Responsabilidade Criminal da Pessoa Jurídica por crimes contra o meio ambiente: um balanço após 27 anos de Constituição, Revista de Direito Ambiental, ano 20, vol.80.

BRANCO, Rilke Tithcliff Pierre (2014). Justiça Policial: a constitucionalização do indiciamento ante os direitos fundamentais e o processo administrativo policial.Ed. Núria Fabris Porto Alegre.

CERQUEIRA, Daniel. \& Lobão, Waldir (2003). Determinantes da criminalidade: uma resenha dos modelos teóricos e resultados empíricos. Rio de Janeiro: IPEA.

CLARKE, Ronald. (1997). Situational Crime Prevention Successful case studies (2nd ed) New York: Harrow and Heston

COUTINHO, Camila Mendes de Santana. (2012). A responsabilidade penal da pessoa jurídica na lei de crimes ambientais: da necessidade de construção dogmática de um sistema de imputação penal autônomo do sujeito coletivo. Dissertação de mestrado, UFPE, 2012).

CRESPO, Eduardo Demetrio (2013). Fundamento da responsabilidade em comissão por omissão dos diretores de empresas, IBCCRIM.

FELICIANO, Guilherme Guimarães (2013). Revista da Faculdade de Direito, $n^{\circ}$ 108, p.491/528. Jan/dez. Universidade de São Paulo.

FREITAS, Vladimir Passos de. (2006). A contribuição da Lei dos crimes Ambientais na defesa do Meio Ambiente, Revista CEJ.

FREITAS, Gizele Luzia de Mello de; Spenger, Adriana Maria Gomes de Souza. A possibilidade de responsabilização penal exclusiva da pessoa jurídica em crimes ambientais. Revista Eletrônica de iniciação Científica. Itajaí, Centro de Ciências Sociais e Jurídicas da UNIVALI, v. 4, n.1, p. 921-942, $1^{\circ}$ trimestre de 2013. 
GOMEZ-JARA, Carlos. "Responsabilidad penal de todas las personas jurídicas? Una antecrítica al símil de la ameba acuñado por Alex van Weezel". Polít. crim. Vol. 5, No 10 (Diciembre 2010), Doc. 1, pp. 455-475.

GOMEZ-JARA, Carlos (2015). A responsabilidade penal da pessoa jurídica - Teoria do Crime para Pessoas Jurídicas, Ed. Atlas, São Paulo.

HEINE, Gunther. La responsabilidad penal de las empresas: evolucion internacional y consecuencias nacionales, in https://www.unifr. ch/ddp1/derechopenal/anuario/an_1996_04.pdf

LEITE, José Rubens Morato. Bello Filho, Ney de Barros (2004) Direito Ambiental Contemporâneo.

LIMA, Renato Brasileiro de (2016). Legislação Criminal Especial Comentada, Ed. Jus Podivm, Salvador.

MACHADO, Paulo Affonso Leme (2014). Direito Ambiental Brasileiro, 22 ${ }^{\mathrm{a}}$ ed. Malheiros: São Paulo.

MOREIRA, Romulo Andrade (2016). O indiciamento e o STF. Repertório de Jurisprudência RJ 3.01/12 no 9.

KASPAR, Johannes. (2013). Corporate Criminalogy- Causes and Prevention of Corporate Crime (Vol.3) Kyushu University Legal Research Bulletin

PUIG, Santiago Mir (2004). Una tercera vía en materia de responsabilidad penal de las personas juridicas, in RECPC 06-01.

SANCHES, Rogério (2014). Manual de Direito Penal. $2^{a}$ ed. Ed. Jus Podivm, Salvador,

SARCEDO, Leandro. (2014). Compliance e responsabilidade penal da pessoa jurídica: construção de um novo modelo de imputação baseado na culpa corporativa (Dissertação de doutorado, Universidade de São Paulo, 2014).

WEISSMANN, Andrew. (2007). Rethinking Criminal Corporate Liability. Indiana Law Journal

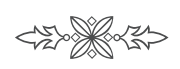

